\title{
STIMULATION OF REPRODUCTIVE GROWTH IN RAINBOW TROUT (ONCORHYNCHUS MYKISS) FOLLOWING EXPOSURE TO TREATED SEWAGE EFFLUENT
}

\author{
Birgit Höger, $\dagger$ Sean TAylor, $\$$ Betrina HitzFeld, $\S$ Daniel R. Dietrich, $\|$ and \\ MICHAEL R. VAN DEN HEUVEL*\# \\ †European Centre for the Validation of Alternative Methods, Institute of Health and Consumer Protection of the European Commission Joint \\ Research Centre, 21020 Ispra, Italy \\ ¥Scion, Private Bag 3020, Sala Street, Rotorua, New Zealand \\ $\S$ Swiss Agency for the Environment, Forests and Landscape, CH-3003 Bern, Switzerland \\ ||Environmental Toxicology; University of Konstanz, D-78547 Konstanz, Germany \\ \#University of Prince Edward Island, Department of Biology, Charlottetown C1A 4P3, Canada
}

\begin{abstract}
Rainbow trout (Oncorhynchus mykiss) were exposed to 1.5 and $15 \%$ v/v secondary treated sewage eflluent for 32 weeks in flow-through mesocosms. The exposure encompassed the full period of reproductive development for rainbow trout. Trout did not show any evidence of a dose-dependent change in growth. Fish exposed to $15 \%$ effluent were the only group to show mortality (5\%) over the duration of the experiment. Trout at the highest effluent concentration had significantly higher liver size than reference water fish. Both male and female trout in the $15 \%$ exposure group also exhibited significantly higher gonad weight than the reference group. In female trout, this gonad size increase could be explained by higher egg numbers. Female and male trout both displayed a significant increase in plasma $17 \beta$-estradiol levels after exposure to $15 \%$ effluent, while neither sex had dose-dependent differences in plasina testosterone. Male trout displayed elevated vitellogenin levels and reduced plasma 11-ketotestosterone concentration after exposure to $15 \%$ effluent. Chemical examination of steroidal compounds, including both estrogens and androgens, in the wastewater revealed that only estrone was detectable at a mean concentration of $4.5 \mathrm{ng} / \mathrm{L}$. It is assumed that the effects observed in trout exposed to $15 \%$ effuent were consistent with stimulation of reproductive development due to very low levels of estrogens. Overall, long-term exposure to treated sewage effluent containing low levels of estrogen did not have significant negative implications for reproductive development in rainbow trout.
\end{abstract}

Keywords-Fish Endocrine Sewage wastewater Reproduction Hormone

\section{INTRODUCTION}

Impacts on the reproductive physiology of fishes exposed to municipal sewage effluent was one of a number of observations that culminated in a global level of concern for endocrine-disrupting chemicals in the environment. Fish with male and female germ cells within the same gonad, also known as intersex, were first observed in municipal wastewater treatment lagoons in the United Kingdom [1]. Further observations of the induction of the yolk protein vitellogenin in male fish suggested that these effects are mediated by estrogens present in the ambient waters. Follow-up studies demonstrated that estrogenic effects could be found in a number of aquatic environments receiving sewage effluent in the United Kingdom $[2,3]$. Those initial observations prompted a substantial number of studies carried out on endocrine disruption around the world, and these have been extensively reviewed [4-6]. Despite the knowledge gained over the past decade, it has been concluded that many studies do not address a number of key scientific issues surrounding endocrine-disrupting compounds $[5,6]$. Low levels of pure estrogens can certainly impact on reproduction in multigenerational laboratory studies [7]. However, questions exist regarding whether exposure to low levels of estrogens in complex effluent mixtures are causing effects to individuals and populations in the field.

It is certainly clear from the large number of studies that

\footnotetext{
* To whom correspondence may be addressed (mheuvel@upei.ca).
}

continuous exposure of aquatic organisms to low levels of potent hormones can have measurable effects, such as induction of vitellogenin in male or immature fish [8], alterations in steroid hormone levels [9], or changes in external reproductive characteristics [1.0]. Estrogenic substances most likely responsible for these observations have been well characterized in sewage effluent [11]. Three major estrogens, 17 $\beta$-estradiol, estrone, and the synthetic hormone $17 \alpha$-ethinylestradiol, are present in sewage effluent in low $\mathrm{ng} / \mathrm{L}$ quantities $[12,13]$, and subsequent studies have verified that these potent steroids can cause biological effects at such low concentrations [14].

Apart from the initial studies documenting intersex in the United Kingdom, severe reproductive consequences derived from complex, estrogen-containing effuents in the field have not been reported. Studies have led to the conclusion that severe impacts of endocrine disruptors on the population level remain questionable ([15]; http://europa.eu.int/comm/research/ endocrine/projects_completed_en.html) or have concluded that the impact of sewage effluent on reproduction in adult fishes is quite minor $[16,17]$. A study using pure estrogens showed that induction even of high levels of vitellogenin in male cunner (Tautogolcbrus adspersus) does not cause significant reproductive alterations [18], although high levels of plasma vitellogenin have been associated with liver damage in flounder (Paralichthys dentatus) [19].

The present study addressed the key question of the rele- 
Table 1. Chemical characteristics of Rotorua (New Zealand) sewage effluent over the study period (September 22, 2001-May 12, 2002)

\begin{tabular}{lc}
\hline Parameter & $\begin{array}{c}\text { Mean concn., mg/L } \\
\text { (range, } n \text { ) }\end{array}$ \\
\hline Chemical oxygen demand & $52.4(18.4-504.5,45)$ \\
Biochemical oxygen demand & $10.4(2-168,60)$ \\
Chloride & $46.6(37.8-77.6,60)$ \\
Ammonia nitrogen & $0.31(0.01-2.2,62)$ \\
Total reactive phosphorus & $4.8(0.5-8.2,62)$ \\
Total oxidized nitrogen as $N$ & $7.7(5.6-10.0,62)$ \\
Total kjeldahl nitrogen as $\mathrm{N}$ & $2.9(1.5-30,60)$ \\
Organic nitrogen as N & $2.7(1.3-30.2,60)$ \\
Total phosphorus & $5.5(1.3-24.9,60)$ \\
Total nitrogen (oxidized $+\mathrm{kjeldahl})$ & $10.7(7.7-37.8,60)$ \\
Suspended solids & $19.6(3.6-445,60)$ \\
pH & $7.2(6.9-7.5,60)$ \\
\hline
\end{tabular}

vance of long-term exposure to sewage effuent on the reproductive development in rainbow trout (Oncorhynchus mykiss). In order to eliminate confounding environmental factors such as energy intake and exposure concentrations, mesocosms were used allowing for controlled rations and effluent exposure concentrations. The study was conducted over an adult reproductive growth cycle, and trout were exposed to environmentally relevant concentrations of effluent from a modern municipal wastewater treatment plant. By this means, the reproductive development of adults of this species in response to effluent exposure could be examined.

\section{MATERIAIS AND METHODS}

\section{Experimentul design}

Two-year-old rainbow trout were exposed to a nominal concentration of either diluent water, $1.5(\mathrm{v} / \mathrm{v})$, or $15 \%(\mathrm{v} / \mathrm{v})$ effluent in randomly selected replicate 12,000 - $\mathrm{L}$ tanks containing 50 individuals each (total of six tanks). The sex of trout could not be determined externally at the onset of the experiment; thus, the proportion of males and females was randomly determined. This particular strain of rainbow trout is characterized by a subpopulation that does not mature until four years of age. The sex/maturity distribution as determined at the conclusion of the experiment was $32 \%$ immature, $32.5 \%$ females, and $35.5 \%$ males for all treatments combined. The measured coefficient of variation of biomass between individual tanks at the onset of the experiment was $3.6 \%$. The initial experiment loading rate of trout biomass, based on total nominal flow rate, was $1.1 \mathrm{~g} / \mathrm{L} / \mathrm{d}$. Because of growth increases, the final loading rate by the termination of the experiment was $2.2 \mathrm{~g} / \mathrm{L} / \mathrm{d}$.

Activated carbon dechlorinated tap water was used as the diluent and as the reference treatment (aquifer source). Two replicate fish tanks were used for each treatment. Trout exposure tanks were provided with a constant water flow of 10 $\mathrm{L} / \mathrm{min}$, which resulted in a $95 \%$ replacement time of approximately $45 \mathrm{~h}$. Final treated effluent was obtained every $2 \mathrm{~d}$ from a municipal sewage treatment plant located in Rotorua, New Zealand. This treatment facility employs a pretreatment step with stop screens and a grit trap, a primary treatment step with sedimentation, and secondary activated sludge treatment (Bardenpho Reactor).

All trout were tagged with individually numbered T-bar type tags (HallPrint, Holden Hill, SA, Australia) and fish weight and length were recorded at the start of the experiment. Trout were fed daily with commercial feed pellets (Reliance stock food, Dunedin, New Zealand) at a ratio of $0.7 \%$ of the wet body weight, and this ration was adjusted monthly to compensate for growth. The exposure was performed between September 2001 and May 2002. After exposure for 26 weeks, trout were anesthetized with ethyl-3-aminobenzoate methanosulfonate (MS222; Fluka, Buchs, Switzerland), and $1 \mathrm{ml}$ of blood was taken by syringe from the caudal vein. Fish were exposed for a further six weeks until sampled.

On final sampling, fish were anesthetized, and blood for plasma samples was removed by caudal puncture and collected in heparinized vacutainers. These samples were kept on ice and later spun at $1,000 \mathrm{~g}\left(10 \mathrm{~min}, 4^{\circ} \mathrm{C}\right)$ to obtain plasma, which was then kept at $-80^{\circ} \mathrm{C}$ pending analysis. Body weight, length, liver, spleen, and gonad weights were recorded. A 3- to 5-g sample of ovary for fecundity analysis was weighed and then frozen until egg counts could be made.

\section{Water chemistry}

Chemical characterization of effluent quality was provided by the Rotorua District Council (Rotorua, New Zealand) (Table 1). In addition, dissolved oxygen, $\mathrm{pH}$, and conductivity in the fish exposure tanks and in undiluted effluent were measured daily. Aeration was provided in the effluent holding tanks and the trout exposure tanks resulting in a mean ( \pm standard deviation [SD]) $9.51 \pm 0.38 \mathrm{mg}$ dissolved oxygen (DO)/L, 9.65 $\pm 0.38 \mathrm{mg} \mathrm{DO} / \mathrm{L}$, and $9.64 \pm 0.34 \mathrm{mg} \mathrm{DO} / \mathrm{L}$ in control, $1.5 \%$, and $15 \%$ exposure tanks, respectively, as indicated by daily measurements. The $\mathrm{pH}$ values in the exposure tanks were comparable for all treatments and ranged between 7.13 and 7.22. Conductivity was used to calculate the actual effluent concentration in the fish tanks daily: the mean \pm SD measured daily concentrations were $1.1 \pm 0.5 \%$ and $13.6 \pm 3.2 \% \mathrm{v} / \mathrm{v}$ for the $1.5 \%$ and $15 \% \mathrm{v} / \mathrm{v}$ nominal concentrations, respectively (Fig. 1a). Temperature was measured hourly using Onset Tidbit tem-
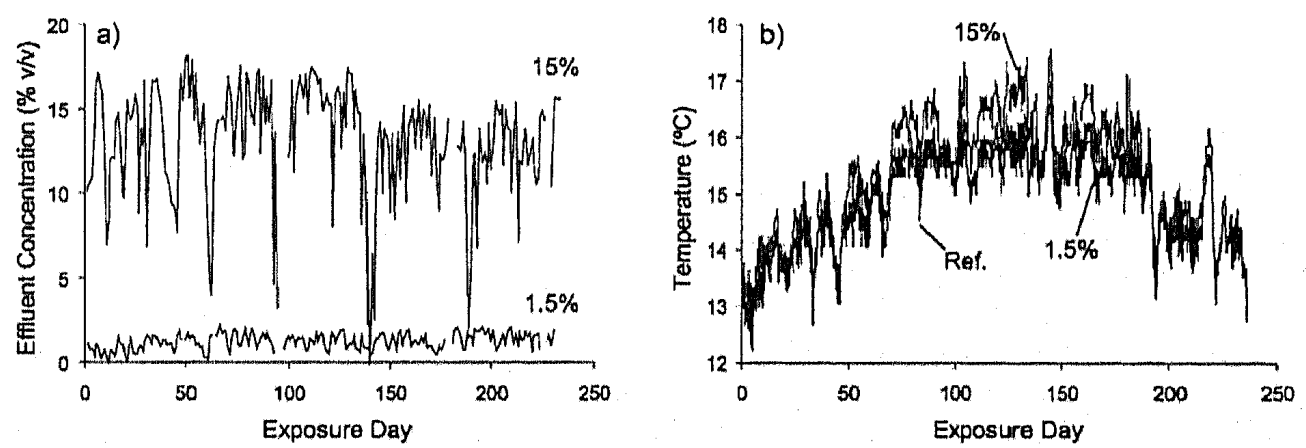

Fig. 1. (a) Effluent concentration calculated from conductivity measurements and (b) temperature in trout exposure tanks during the course of the exposure. 
perature loggers (Onset Computer Corporation, Bourne, MA, USA). The mean $\pm S D$ temperatures were $14.8 \pm 0.8,14.9$ \pm 0.9 , and $15.3 \pm 1.0^{\circ} \mathrm{C}$ for the reference, $1.5 \%$, and $15 \%$ treatments, respectively. Because of the effluent temperature, some increases in temperature in the treatments as compared to the reference group was unavoidable. This was particularly obvious in the warmer summer months (Fig. 1b).

Samples of sewage effuent from the holding tank $(1 \mathrm{~L})$ were collected for analysis of steroidal organic compounds in water on a weekly basis and immediately frozen at $-20^{\circ} \mathrm{C}$. Two pooled samples of $10 \mathrm{~L}$ corresponding to the first and second half of the experiment were used for analysis. The samples were filtered with glass-fiber type $\mathrm{C}(\mathrm{GF} / \mathrm{C})$, and filters were ground with $20 \mathrm{~g}$ of anhydrous sodium sulfate $(\mathrm{BDH}$, Poole, Dorset UK), followed by overnight Soxhlet extraction with dichloromethane. The filtrates were adjusted to $\mathrm{pH} 3$, and $500 \mathrm{ml}$ of methanol (Scharlau, Barcelona, Spain) were added to the samples before extraction using an Autotrace solid phase extraction (SPE) Workstation (Zymark, Hopkinton, MA, USA) with SPEC C18 disks (47 mm; Varian, Palo Alto, CA, USA) and $10 \mathrm{ml} / \mathrm{min}$ flow rate. The disks were dried with nitrogen and then eluted with $150 \mathrm{ml}$ of dichloromethane. Extracts from the GF/C filter papers were combined with SPE extracts prior to analysis. Samples were derivatized by adding $50 \mu \mathrm{l}$ of bis(trimethylsilyl) trifluoroacetamide $+1 \%$ trimethylchlorosilane silylation reagent (Alltech, Auckland, New Zealand), using $10 \mu \mathrm{l}$ of dibromoanthracene (TCI, Tokyo, Japan) in pyridine as the internal standard. Analysis was performed on a $6890 \mathrm{~N}$ gas chromatograph and $5973 \mathrm{~N}$ mass selective detector from Agilent Technologies (Palo Alto, CA, USA) on an Agilent Ultra-2 column ( $50 \mathrm{~m} \times 200 \mu \mathrm{m}$ inner diameter, film thickness $0.33 \mu \mathrm{m})$. Samples were corrected for recoveries of a matrix spike.

\section{Plasma steroid and serum vitellogenin levels}

Steroid hormones were measured by standard radioimmunoassay procedures according to McMaster et al. [20]. Testosterone, estradiol, and 11-ketotestosterone (11-KT) were obtained from Sigma (St. Louis, MO, USA), testosterone and estradiol antibodies from ICN (Costa Mesa, CA, USA), and 1 1-KT antibody from Helix Biotech (Vancouver, BC, Canada). Tritiated testosterone and estradiol were purchased from Amersham Life Science (Little Chalfont, Buckhamshire, UK) and tritiated 11-KT from the U.S. Geological Service (Tim Gross, Gainesville, FL, USA). Plasma vitellogenin was measured with a specific rainbow trout VTG EIA kit (Biosense Laboratories, Bergen, Norway).

\section{Statistics}

Condition factor, liver size, gonad size, and fecundity data were analyzed using analysis of covariance (ANCOVA) on logarithmically transformed variables, with body size (length or weight) as the covariate. Liver and gonadosomatic indices were calculated from organ weight and body weight: [organ $w t /($ body wt - organ wt)] $\times 100$. Condition factor was determined from total body weight and total length: [(body wt - organ wt)/length $\left.{ }^{3}\right] \times 100$. Growth data and steroid data were compared using analysis of variance (ANOVA) after logarithmic transformation. The variability of replicate tanks was tested as a variable in all ANOVAs and ANCOVAs and did not add significant yariability for any of the endpoints with the exception of growth. Thus, for most endpoints with the exception of growth, individuals from replicate tanks were pooled for all further analyses. Dunnett's test was used for post hoc comparisons of treatment groups to the reference group. Vitellogenin data did not conform to the assumption of parametric statistics and was analyzed using nonparametric Kruskal-Wallis one-way ANOVA with Bonferroni adjustment for multiple comparisons. A number of samples for vitellogenin measurement were nondetectable, and the detection limit of $5 \mathrm{ng} / \mathrm{ml}$ was assigned to these values. All statistical testing was completed using the Systat $\left.{ }^{(}\right)$software package [21]. The critical level of significance used in determining statistical differences for all analyses was $\alpha=0.05$.

\section{RESULTS}

Mortality, growth, and somatic indices

Mortality during the 26 weeks prior to bleeding was $5.0 \%$ for the $15 \% \mathrm{v} / \mathrm{v}$ treatment. No mortalities occurred in the reference or $1.5 \% \mathrm{v} / \mathrm{v}$ exposure groups. Posthandling mortality occurred because of the bleeding event that took place at 26 weeks of exposure, and since death between 26 and 32 weeks of exposure could not be attributed to effluent exposure alone, mortality during the last six weeks was not considered further in the data evaluation.

Growth was assessed at 26 and 32 weeks of exposure using the calculated percent growth (for both length and weight) of each individually tagged trout (Table 2). A significant increase occurred in length and weight of $1.5 \% \mathrm{v} / \mathrm{v}$ effuent-exposed female trout at 26 weeks. By 32 weeks, this increase was statistically significant for length gain. Thus, no clear dose response in growth was observed in females. Males did not show a similar pattern for growth, and the only statistically significant effect was a decrease in length growth after 32 weeks at $15 \% \mathrm{v} / \mathrm{v}$ effluent, compared to reference treatment. Male trout showed a significant component of variability in growth between replicate exposure tanks for both length and weight increases at all time periods. In females, this tank effect was observed only for weight gain after 32 weeks. Subsequent analysis revealed that this was largely due to variability in growth between the two replicates of the $15 \% \mathrm{v} / \mathrm{v}$ effluent exposures, and this trend was not reflected in the other exposure groups.

No significant effects of exposure to effluent on condition factor were observed after 32 weeks in either male or female trout (Table 2). This condition factor was calculated excluding gonad and organ weights from the total weight of the fish and thus reflects the energy accumulated in somatic body mass excluding reproductive development. At 26 weeks of exposure, the organ sizes could not be determined, so condition factor was not calculated, and changes in gonad growth will confound this measure of somatic energy storage.

Mature male and female trout exposed to $15 \%$ effluent showed significantly higher liver weight as well as significantly higher gonad weight compared to reference trout (Fig. 2). Although the increases were statistically significant only at the highest effluent concentration, these two endpoints increased in a concentration-dependent fashion for both males and females. Female trout exposed to $15 \%$ effluent had increased fecundity as indicated by a higher number of eggs per kilogram body weight (Fig. 3). No differences were observed in the calculated ovarian follicle weight between treatments (data not shown). These observations indicate that increases in gonad size were due to more ovarian follicles per unit body weight as opposed to larger ovarian follicles. No significant differences were observed in spleen weight associated with effluent 
Table 2. Mean \pm standard error of the mean $(n)$ growth in length and weight measured as percent increase over the duration of the experiment, condition factor corrected for organ weight, and spleen somatic index (SSI)

\begin{tabular}{lccc}
\hline Parameter & Reference & $1.5 \%$ Effluent & $15 \%$ Effluent \\
\hline Females & & & \\
Length gain (26 weeks) & $19.9 \pm 1.4(27)$ & $24.2 \pm 1.2(32)^{\mathrm{a}}$ & $20.8 \pm 1.1(21)$ \\
Length gain (32 weeks) & $28.1 \pm 1.6(27)$ & $33.5 \pm 1.2(32)$ & $26.6 \pm 1.2(21)$ \\
Weight gain (26 weeks) & $100 \pm 7(27)$ & $122 \pm 7(32)^{\mathrm{a}}$ & $104 \pm 7(21)$ \\
Weight gain (32 weeks) & $152 \pm 9(27)$ & $190 \pm 8(32)^{\mathrm{a}}$ & $148 \pm 10(21)$ \\
Condition factor (32 weeks) & $1.198 \pm 0.016(26)$ & $1.204 \pm 0.013(32)$ & $1.190 \pm 0.024(21)$ \\
SSI (32 weeks) & $0.039 \pm 0.002(28)$ & $0.031 \pm 0.002(32)$ & $0.036 \pm 0.002(21)$ \\
Males & & & \\
Length gain (26 weeks) & & $24.3 \pm 1.1(21)$ & $21.8 \pm 0.9(29)$ \\
Length gain (32 weeks) & $34.8 \pm 0.7(33)$ & $33.8 \pm 1.5(21)$ & $1.7 \pm 1.6(29)^{\mathrm{a}}$ \\
Weight gain (26 weeks) & $118 \pm 4(33)$ & $173 \pm 10(21)$ & $1.95(29)$ \\
Weight gain (32 weeks) & $166 \pm 5.8(33)$ & $1.283 \pm 0.017(20)$ & $1.289 \pm 0.013(29)$ \\
Conclition factor (32 weeks) & $1.248 \pm 0.012(34)$ & $0.058 \pm 0.003(21)$ & $0.064 \pm 0.004(29)$ \\
SSI (32 weeks) & $0.056 \pm 0.002(34)$ & & \\
\hline
\end{tabular}

"Significant difference from reference group.

b A significant elfect of exposure tank was observed.

concentration in either males or females (spleen somatic index; Table 2).

\section{Plasma steroids and vitellogenin level}

Exposure of rainbow trout to sewage treatment effluent for 26 and 32 weeks led to significantly higher plasma estradiol levels in females at both time periods compared to control fish (Fig. 4). Testosterone levels were significantly elevated in female fish after exposure to $1.5 \%$ effuent for 26 weeks. In male fish, exposure to effluent did not change plasma testosterone levels significantly. However, a statistically significant depression of 11-ketotestosterone was observed at 26 weeks of exposure, but not at 32 weeks of exposure. In order to explore this further, estradiol was also measured in male trout for the reference and $15 \%$ effluent exposure. Estradiol was found to be significantly elevated in male trout exposed to the $15 \%$ effluent (Fig, 5). Moreover, exposure to $15 \%$ effluent increased plasma vitellogenin in males (Fig. 6). A high variability in the induction of vitellogenin synthesis between individuals was observed. Some individuals in the exposure groups were clear- ly induced, while others from the same group showed nondetectable vitellogenin levels.

\section{Water chemistry}

The two pooled effluent samples were analyzed for a suite of sterodial compounds including estradiol, estrone, ethinylestradiol, testosterone, pregnenolone, progesterone, androstenedione, and androstadienedione. Estriol recovery was poor with the method applied, and it was not included in the suite of analytes. With the exception of estrone, the concentrations of all other steroids were below their respective limits of detection $(\sim 0.5 \mathrm{ng} / \mathrm{L}$ ). The concentration of estrone was 2 and $7 \mathrm{ng} / \mathrm{L}$ for the first and second half of the experiment, respectively. An unknown compound with similar ions coeluted with ethinylestradiol. As the ion ratios were inconsistent with ethinylestradiol, it was not identified as such.

\section{DISCUSSION}

Chronic exposure of rainbow trout to treated sewage effluent resulted in increased mortality and alterations of general
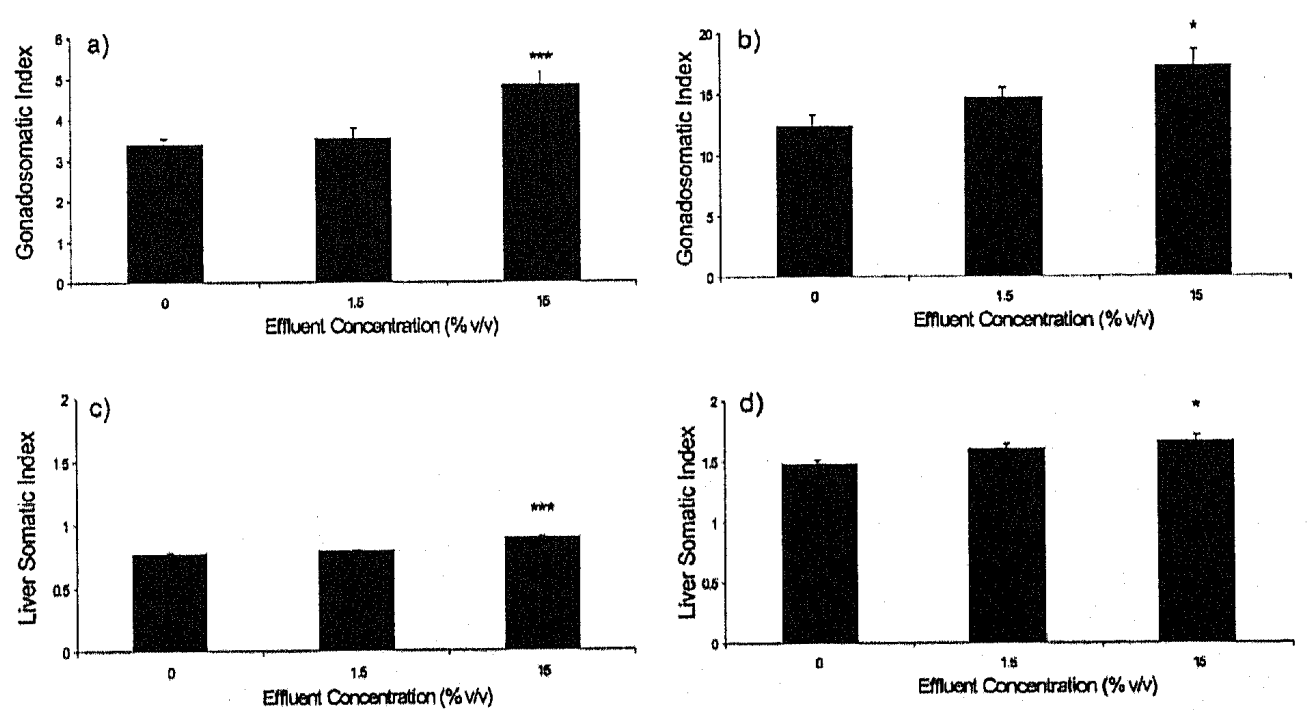

Fig. 2. Mean gonadosomatic index for (a) mature male and (b) mature females and liver somatic index for (c) mature males and (d) mature female trout after 32 weeks of exposure to treated sewage effluent. Error bars indicate the standard error of the mean. Data were tested using one-way analysis of variance with Dunnett's posttest. $n \geq 21 ; * p<0.05$, *** $p<0.001$. 


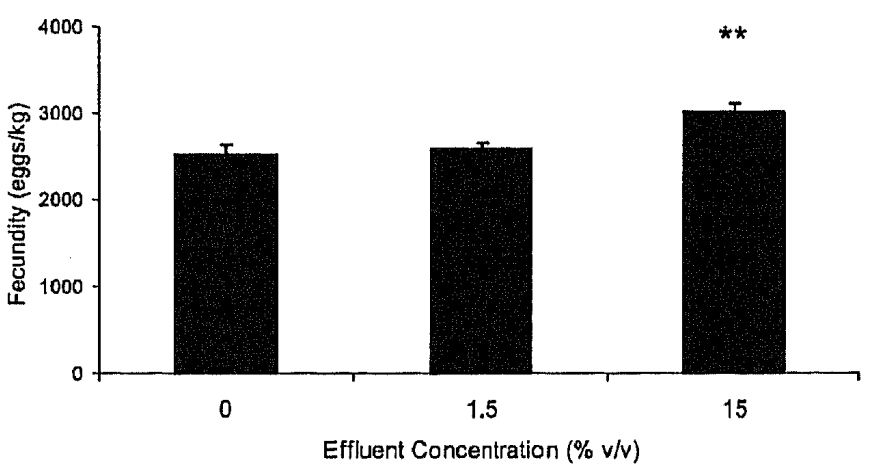

Fig. 3. Mean fecundity corrected for body weight in female trout exposed to sewage eftluent. Error bars indicate standard error of the mean. Data were tested using one-way analysis of variance with Dunnett's posttest. $n \geq 21$; $* * *<<0.01$.

physiological and endocrine-reproductive endpoints. Reproductive alterations included a stimulation of gonad growth in both males and females and higher fecundity in females. Female trout displayed augmented plasma $17 \beta$-estradiol and unchanged levels of testosterone. In mature males, plasma testosterone and 11-ketotestosterone levels were not changed with the exception of lower 11-ketotestosterone at 26 weeks. An increase in plasma $17 \beta$-estradiol and serum vitellogenin levels was observed in males after 32 weeks of effluent exposure, consistent with a response to the low levels of estrogens measured in this effluent.

Some mortality did occur in the highest-exposure group in this study, and one must bear in mind when assessing the subtle effects of effuent that acute impacts are still relatively common with sewage effluents. The suspected contaminant most likely causing mortality in this study was ammonia, as effluent ammonia was high in some instances during the experiment. Indeed, ammonia has been observed to cause mortality in trout at concentrations below $1 \mathrm{mg} \mathrm{NH}-\mathrm{N} / \mathrm{L}$ [22], and ammonia concentrations in the effluent used in the present study were above $1 \mathrm{mg} / \mathrm{L}$ at some instances, with a peak concentration of $2.0 \mathrm{mg} / \mathrm{L}$ at the time the first mortalities occurred.
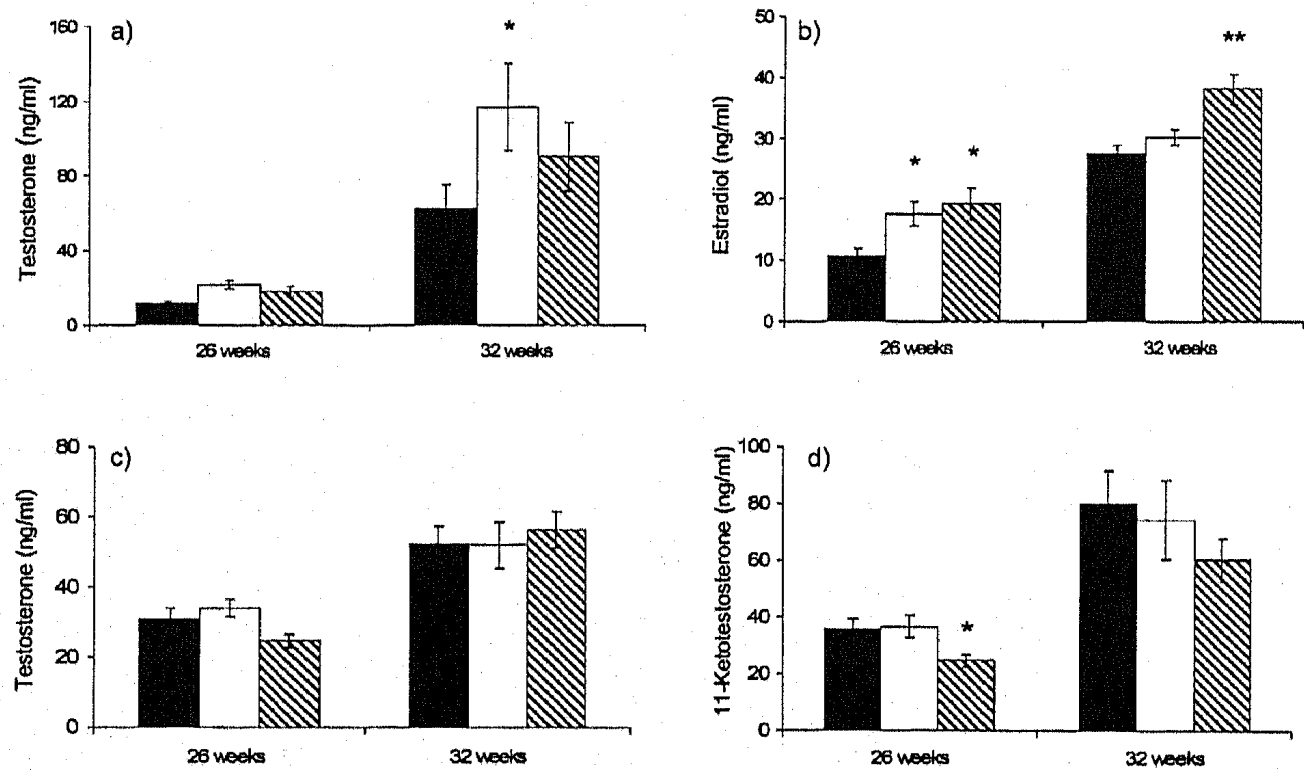

Fig. 4. Mean steroid hormone concentrations for (a) testosterone in females, (b) estradiol in females, (c) testosterone in males, and (d) 11ketotestosterone in males. Solid bars are the referemce group, open bars $1.5 \%$ (v/v) effluent, and hatched bars $15 \%$ (v/v) effluent. Error bars indicate standard error of the mean. Data were tested using one-way analysis of variance with Dunnett's posttest. $n=12 ; * p<0.05$. 


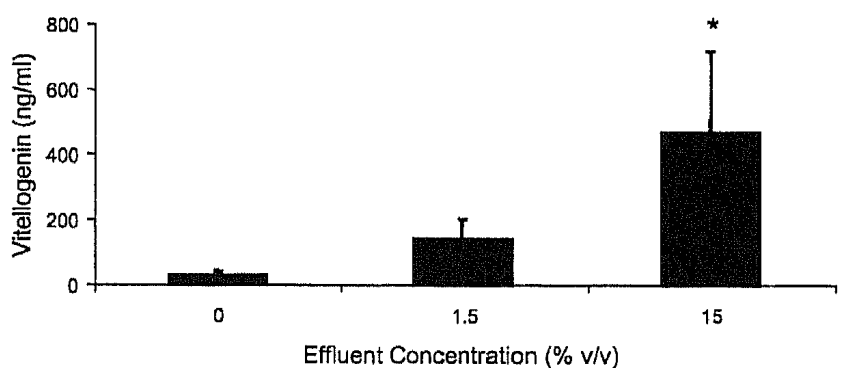

Fig. 6. Median ( \pm standard error of the mean) values for vitellogenin in plasma samples of mature male trout after exposure to sewage effluent for 32 weeks. Data were tested using Kruskal-Wallis nonparametric one-way analysis of variance with Bonferroni adjustment for multiple comparisons. $n=12 ; * p<0.05$.

New Zealand). Based on 500 million cubic meters of effluent per year ([24]; http://www.mfe.govt.nz/publications/waste/ nat-waste-data-report-sum-sept97.pdf), an average concentration of $3 \mathrm{ng} / \mathrm{L}$ could be expected if all of it reaches the final eftluent. Given treatment removal, other losses, and detection limits in the range of $1 \mathrm{ng} / \mathrm{L}$, it is reasonable to assume that $\mathrm{EE}_{2}$ cannot be detected in treated wastewater. Also in line with our findings, a recent report states that $\mathrm{EE}_{2}$ could be rarely detected in sewage effluents within the European Union and that estrone was the most commonly found estrogen [15]. Moreover, it should be indicated that our measurement of ethinylestradiol was also inhibited by an interfering peak with similar major ions. This is in accordance with observations of an unidentified interfering compound, described by Ternes et al. [12]. Although $E_{2}$ cannot be detected, this does not preclude biological effects, as the threshold of effects can be as low as $0.1 \mathrm{ng} / \mathrm{L}$ [25]. A study describing sex reversal in male zebrafish after chronic exposure to a concentration of $0.6 \mathrm{ng}$ $\mathrm{EE}_{2} / \mathrm{L}$ came to a similar conclusion [15].

The changes in steroid hormones in effluent-exposed trout observed in the present study are in line with studies with sewage effluent in the United States [9], where elevated plasma estradiol levels and unchanged testosterone levels in female walleye (Stizostedion vitreum) were observed. Estrogenic activity has been shown for several sewage effluents in various countries, including New Zealand [26]. However, contradiccory results are often found for single parameters, such as gonad weight. In a study with sexually maturing male tish, Harries et al. [27] found that exposure to effluent from a UK sewage treatment plant led to significantly increased plasma vitellogenin level but did not affect testis weight in those fish, while in a previous study [2], exposure to effluent led to smaller gonad indices. Hemming et al. [28] found that exposure to sewage effluent led to lower gonadosomatic index and higher vitellogenin levels in male fathead minnow (Pimephales promelas); however, the effluent concentrations of up to $100 \%$ used were quite high. These studies and the one described herein are consistent with exposure to estrogens in sewage effluent, and some of the differences in the observed effects can be explained by the complexity of hormonal regulatory axis. The differences between the physiological changes in the species studied are likely reflective of the concentrations of estrogenic compounds in the respective effluents, though species sensitivity differences could also be a factor.

Although the initiation of reproductive development is poorly understood, estrogens are thought to be the primary hormone responsible for the initiation of the gonadal growth process in both male and female fish. Estrogens can lead to the activation of brain aromatase [29], which in turn has a role in the regulation of gonadotropin-releasing hormone or inhibitors of gonadotropin-releasing hormone. This mechanism may explain why both male and female trout showed elevated gonad size. The recruitment of additional ovarian follicles in female trout exposed to $15 \%$ effuent provides evidence that such an endocrine mechanism may be causative of the reproductive changes. Presumably, the ability to recruit follicles will be a function of gonadotropin concentrations. Low levels of estrogens may have had a stimulatory effect on the production and secretion of those gonadotropins. As with many endocrine disruptors, there would have been a narrow window of development over which this is possible. Exposure after vitellogenesis was initiated may not have resulted in similar changes. In a similar fashion, a previous study with rainbow trout exposed to pulp and paper mill effuent has shown that this fish species is most sensitive to alterations in gonad growth when exposed during the period of gamete recruitment [30].

The relatively low level of vitellogenin induction in male trout is consistent with the low-level estrogen exposure suggested by direct chemical measurements in effluent samples. This modest level of vitellogenin induction is insufficient information to conclude whether this particular endpoint is related to or predictive of either higher-level reproductive effects or toxicological effects on other physiological systems. Our study also showed an increase in liver somatic index in male and female trout after exposure to $15 \%$ effluent. Several studies on endocrine effects showed that fish exposed to sewage effluent displayed enlarged livers, which was linked to the production of vitellogenin [31]. Liver size, however, can be impacted by many factors, particularly energy storage increases. As the exposed fish were on controlled rations and physiological data such as condition factor or growth did not show other indications of increases in energy storage, it is difficult to attribute this change to increased energy storage in the liver. Thus, it is more likely that the increased liver size is due to increased biosynthesis in the liver, related in part to reproductive functions as well as contaminant metabolism, such as 7 -ethoxyresorufin- $O$-deethylase activity, which was induced in male trout exposed to $15 \%$ effluent [32].

This study was conducted along with a series of parallel studies to examine the potential of Rotorua sewage effluent to impact on the immune system of rainbow trout. High concentrations up to $70 \% \mathrm{v} / \mathrm{v}$ effluent caused fragility of red blood cell, elevated liver mono-oxygenases, and affected lymphocyte numbers and proliferation [33]. Immune endpoints examined in the same rainbow trout sampled in this paper showed a constant unspecific stimulation of different leucocyte populations in immune organs reminiscent of chronic inflammation [34]. Decreases in serum lysozyme and circulating lymphom cytes were also observed only in female trout from this experiment [32].

In conclusion, the present study demonstrated alterations in endocrine-reproductive and general physiological parameters after exposure to environmentally relevant effluent concentrations. The estrogenic effects of sewage effluent observed in our study can most likely be attributed to exposure to low levels of natural and synthetic steroids of human origin [15]. Overall, the exposure to sewage effuent containing low levels of estrogens caused subtle reproductive effect that should not be a significant concern for the integrity of natural populations. However, an increased frequency of mortality, in combination with previous published information on immune impacts due 
to effluent exposure, may be of concern if it were to occur in exposed populations.

Acknowledgement-The study was supported by the Universitaetsgesellschaft e.V., University of Konstanz, the German Federal Environmental Foundation, the Foundation for Research Science and Technology (New Zealand), and a New Zealand Royal Society, International Science and Technology Linkages Fund travel grant. The authors would like to thank Rosanne Ellis, Megan Finley, and Murray Smith for practical help; Tim Charleson for chemical analysis; and Fred Leusch for reviewing this manuscript.

\section{REFERENCES}

1. Purdom CE, Hardiman PE, Bye VJ, Eno NC, Tyler CR, Sumpter JP. 1994. Estrogenic effects of effluents from sewage. $J$ Chem Ecol 8:275-285.

2. Harries JE, Sheahan DA, Jobling S, Matthiessen P, Neall P, Sumpter JP, Tyler T, Zaman N. 1997. Estrogenic activity in five United Kingdom rivers detected by measurement of vitellogenesis in caged male trout. Environ Toxicol Chem 16:534-542

3. Jobling S, Nolan M, Tyler CR, Brighty GC, Sumpter JP. 1998. Widespread sexual disruption in wild fish. Environ Sci Technol 32:2498-2506.

4. Tyler CR, Jobling S, Sumpter JP. 1998. Endocrine disruption in wildlife: A critical review of the evidence. Crit Rev Toxicol 23: 319-361.

5. Sumpter JP, Johnson AC. 2005. Lessons from endocrine disruption and their application to other issues concerning trace organics in the aquatic environment. Environ Sci Technol 39:4321-4332.

6. Mills LJ, Chichester C. 2005. Review of evidence: Are endocrinedisrupting chemicals in the aquatic environment impacting fish populations? Sci Total Environ 343:1-34.

7. Nash JP, Kime DE, Van der Ven LTM, Wester PW, Brion F, Maack G, Stahlschmidt-Allner P, Tyler CR. 2004. Long-term exposure to environmental concentrations of the pharmaceutical ethynylestradiol causes reproductive failure in fish. Environ Health Perspect 112:1275-1283.

8. Folmar LC, Denslow ND, Rao V, Chow M, Crain DA, Enblom J, Marcino J, Guillette LJ Jr. 1996. Vitellogenin induction and reduced serum testosterone concentrations in feral male carp $(C y$ prinus carpio) captured near a major metropolitan sewage treatment plant. Environ Health Perspect 104:1096-1 101.

9. Folmar LC, Denslow ND, Kroll K, Orlando EF, Enblom J, Marcino J, Metcalfe C, Guillette LJ Jr. 2001. Altered serum sex steroids and vitellogenin induction in walleye (Stizostedion vitreum) collected near a metropolitan sewage treatment plant. Arch Environ Contam Toxicol 40:392-398.

10. Batty J, Lim R. 1999. Morphological and reproductive characteristies of male mosquitofish Gambusia affinis holbrooki inhabiting sewage contaminated waters in New South Wales, Australia. Arch Environ Contam Toxicol 36:301-307.

11. Desbrow C, Routledge EJ, Brighty GC, Sumpter JP, Waldock M. 1998. Identification of estrogenic chemicals in STW effluent: 1 . Chemical fractionation and in vitro biological screening. Environ Sci Technol 32:1549-1558.

12. Ternes TA, Stumpf M, Mueller J, Haberer K, Wilken RD, Servos M. 1999. Behavior and occurrence of estrogens in municipal sewage treatment plants-I. Investigations in Germany, Canada and Brazil. Sci Total Environ 225:81-90.

13. O'Brien E, Dietrich DR. 2004. Hindsight rather than foresight: Reality vs. the EU draft guidelines on pharmaceuticals in the environment. Trends Biotechnol 22:326-330.

14. Metcalfe CD, Metcalfe TL, Kiparissis Y, Koenig BG, Khan C, Hughes R.T, Croley TR, March RE, Potter T. 2001. Estrogenic potency of chemicals detected in sewage treatment plant effluents as determined by in vivo assays with Japanese medaka (Oryzias latipes). Environ Toxicol Chem 20:297-308.

15. Pickering AD. 2002. Community programme of research on endocrine disruptors and environmental hormones (COMPREHEND). European Community contract report ENV4-CT-98. Brussels, Belgium.
16. Nichols KM, Miles-Richardson SR, Snyder EM, Giesy JP. 1999. Effects of exposure to municipal wastewater in situ on the reproductive physiology of the fathead minnow (Pimephales promelas). Environ Toxicol Chem 18:2001-2012.

17. Schoenfuss HL, Levitt J'T, Van Der Kraak G, Sorensen PW. 2002. Ten-week exposure to treated sewage discharge has relatively minor, variable effects on reproductive behavior and sperm production in goldfish. Environ Toxicol Chem 21:2185-2190.

18. Mills LJ, Gutjahr-Gobell RE, Borsay Horowitz D, Denslow ND, Chow MC, Zaroogian GE. 2003. Relationship between reproductive success and male plasma vitellogenin concentrations in cunner, Tautogolabrus adspersus. Environ Health Perspect 111: 93-99.

19. Folmar LC, Gardner GR, Schreibman MP, Magliulo-Cepriano L, Mills LJ, Zaroogian G, Gutjahr-Gobell R, Haebler R, Horowitz DB, Denslow ND. 2001. Vitellogenin-induced pathology in male summer flounder (Paralichthys dentatus). Aquat Toxicol 51:431441 .

20. McMaster ME, Munkittrick KR, Van Der Kraak GJ. 1992. Protocol for measuring circulating levels of gonadal sex steroid in fish. Canadian Technical Report of Fisheries and Aquatic Sciences 1836. Fisheries and Oceans, Burlington, ON, Canada.

21. Wilkinson L. 1990. Systat: The System for Statistics. Systat, Evanston, IL, USA.

22. Milne I, Seager J, Mallett M, Sims I. 2000. Effects of short-term pulsed ammonia exposure on fish. Environ Toxicol Chem 19: 2929-2936.

23. Sarmah AK, Northcott GL, Leusch FDL, Tremblay LA. 2005. A survey of endocrine distupting chemicals (EDCs) in municipal sewage and animal waste effuents in the Waikato region of New Zealand. Sci Total Environ 355:135-144.

24. Ministry for the Environment. 1997. National Waste Data Report. Wellington, New Zealand.

25. Thorpe KL, Cummings RI, Hutchinson TH, Scholze M, Brighty G, Sumpter JP, Tyler CR. 2003. Relative potencies and combination effects of steroidal estrogens in fish. Environ Sci Technol 37:1142-1149.

26. Leusch FDL, Chapman HF, van den Heuvel MR, Tan BLL, Gooneratne SR, Tremblay LA. 2005. Bioassay-derived androgenic and estrogenic activity in municipal sewage in Australia and New Zealand. Ecotoxicol Environ Saf (in press).

27. Harries J, Janbakhsh A, Jobling S, Matthiessen P, Sumpter J, Tyler CR. 1999. Estrogenic potency of effluent from two sewage treatment works in the United Kingdom. Environ Toxicol Chem 18: 932-937.

28. Hemming JM, Waller WT, Chow MC, Denslow ND, Venables B. 2001. Assessment of the estrogenicity and toxicity of a domestic wastewater effluent flowing through a constructed wetland system using biomarkers in male fathead minnows (Pimephales promelas Rafinesque, 1820). Environ Toxicol Chem 20:2268-2275.

29. Pasmanik M, Schlinger DA, Callard GY. 1988. In vivo steroid regulation of aromatase and 5-alpha-reductase in goldfish brain and pituitary. Gen Comp Endocrinol 71:175-182.

30. van den Heuvel MR, Ellis RJ. 2002. Timing of exposure to a pulp and paper effluent influences the manifestation of reproductive effects in rainbow trout. Environ Toxicol Chem 21:23382347.

31. Porter CM, Janz DM. 2003. Treated municipal sewage discharge affects multiple levels of biological organization in fish. Ecotoxicol Environ Saf 54:199-206.

32. Höger B, Hitzfeld B, Köllner B, Dietrich DR, van den Heuvel MR. 2005. Sex and low-level sampling stress modify the impacts of sewage effluent on the rainhow trout (Oncorhynchus mykiss) immune system. Aquat Toxicol 73:79-90.

33. Höger B, Köllner B, Kotterba $G$, van den Heuvel MR, Hitzfeld $B$, Dietrich DR. 2004. Influence of chronic exposure to treated sewage effuent on the distribution of white blood cell populations in rainbow trout (Oncorhynchus mykiss) spleen. Toxicol Sci 82: 97-105.

34. Höger B, van den Heuvel MR, Hitzfeld B, Dietrich DR. 2004. Effects of treated sewage effluent on immune function in rainbow trout (Oncorhynchus mykiss). Aquat Toxicol 70:345-355. 